\title{
Inapropriate use of antibiotics effective against gram positive microorganisms despite restrictive antibiotic policies in ICUs: a prospective observational study
}

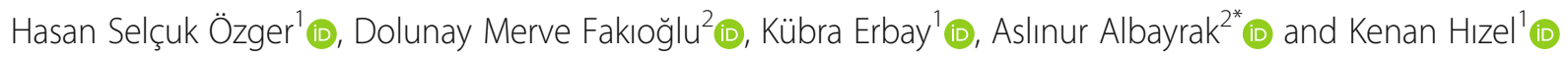

\begin{abstract}
Background: Gram-positive spectrum antibiotics such as vancomycin, teicoplanin, daptomycin, and linezolid are frequently used in empirical treatment combinations in critically ill patients. Such inappropriate and unnecessary widespread use, leads to sub-optimal utilisation. However they are covered by the antibiotics restriction programme. This prospective observational study, evaluates gram-positive anti-bacterial utilisations in intensive care units (ICUs) with various evaluation criteria, to determine the frequency of inappropriate usage and the intervention targets required to ensure optimum use.

Methods: This clinical study was conducted prospectively between 01.10 .2018 and 01.10 .2019 in the medical and surgical ICUs of Gazi University Faculty of Medicine Hospital, Turkey. The total bed capacity was 55 . Patients older than 18 years and who were prescribed gram-positive spectrum antibiotics (vancomycin, teicoplanin, linezolid, and daptomycin) were included. Patients under this age or immunosuppressed patients (neutropenic,- HIV-infected patients with hematologic or solid organ malignancies) were not included in the study. During the study period, 200 treatments were evaluated in 169 patients. The demographic and clinical features of the patients were recorded. Besides observations by the clinical staff, the treatments were recorded and evaluated by two infectious diseases specialists and two clinical pharmacists at 24-h intervals from the first day to the last day of treatment. SPSS software for Windows, (version 17, IBM, Armonk, NY) was used to analyse the data. Categorical variables were presented as number and percentage, and non-categorical variables were presented as mean \pm standard deviation.
\end{abstract}

Results: It was found that inappropriate gram-positive antibiotic use in ICUs was as high as $83 \%$ in terms of noncompliance with the selected quality parameters. Multivariate analysis was performed to evaluate the factors associated with inappropriate antibiotic use, increased creatinine levels were found to increase the risk of such use.

Conclusions: In spite of the restricted antibiotics programme, inappropriate antibiotic use in ICUs is quite common. Thus, it is necessary to establish local guidelines in collaboration with different disciplines for the determination and follow-up of de-escalation of such use and optimal treatment doses.

Keywords: Antibiotic stewardship, Rational antibiotic use, Antibiotic resistance, Gram positive microorganisms, Inappropriate antibiotic use

\footnotetext{
* Correspondence: a.albayrak007@gmail.com

${ }^{2}$ Faculty of Pharmacy, Department of Clinical Pharmacy, Gazi University, Ankara, Turkey

Full list of author information is available at the end of the article
}

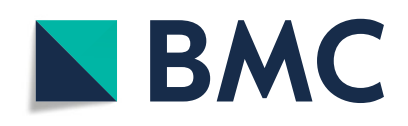

( ) The Author(s). 2020 Open Access This article is licensed under a Creative Commons Attribution 4.0 International License, which permits use, sharing, adaptation, distribution and reproduction in any medium or format, as long as you give appropriate credit to the original author(s) and the source, provide a link to the Creative Commons licence, and indicate if changes were made. The images or other third party material in this article are included in the article's Creative Commons licence, unless indicated otherwise in a credit line to the material. If material is not included in the article's Creative Commons licence and your intended use is not permitted by statutory regulation or exceeds the permitted use, you will need to obtain permission directly from the copyright holder. To view a copy of this licence, visit http://creativecommons.org/licenses/by/4.0/. The Creative Commons Public Domain Dedication waiver (http://creativecommons.org/publicdomain/zero/1.0/) applies to the data made available in this article, unless otherwise stated in a credit line to the data. 


\section{Background}

Infection development is an important cause of morbidity and mortality in intensive care units (ICUs), leading to the widespread use of antibiotics [1]. It is reported that 41$85 \%$ of ICU patients use at least one antibiotic and antibiotic consumption is 10 times higher in ICUs compared to other units [2]. This widespread usage increases the unnecessary and inappropriate use of antibiotics and causes an increase in antimicrobial resistance [3]. Antimicrobial resistance typically increases the risk of poor clinical outcomes and death in ICUs patients [3]. Approximately 20$50 \%$ of hospitalized patients and $30-60 \%$ of patients in ICUs are prescribed unnecessary, inappropriate or suboptimal antibiotic treatment [2-5]. Inappropriate use of empirical antibiotic treatments increases the frequency of early and late period mortality, length of hospital stay and healthcare-associated costs in ICU patients [4]. Antibiotic stewardship programmes are widely used to optimize antibiotic use in hospitals [6, 7]. Implementation of these programmes can lead to significant benefits in terms of clinical outcomes, reduced adverse events and lowered costs $[3,8]$. To develop an effective program, it is necessary to determine the priority targets by evaluating inappropriate antibiotic use [6]. Antibiotic restriction lists should be implemented as part of Antimicrobial Stewardship Programmes (ASPs) and should be supported by other ASP strategies such as empirical treatment guidelines, de-escalation, preauthorisation and / or prospective audit and feedback [8]. As the effectiveness of antibiotic restriction programmes may decrease over time targetoriented revisions may be required to prevent the overuse or misuse of antibiotics [9].

Gram-positive spectrum antibiotics such as vancomycin, teicoplanin, daptomycin, and linezolid are frequently used in empirical treatment combinations in critically ill patients [10]. In Turkey, after beta-lactams and fluoroquinolones, these gram-positive antibiotics are reported to be the most commonly used antibiotics in ICUs [2]. Their widespread use, is thought to be not only inappropriate and unnecessary, but also responsible for sub-optimal utilisation. However, they are covered under the antibiotics restriction programme.

This prospective observational study, evaluates grampositive anti-bacterial utilisations in ICUs with various evaluation criteria, the frequency of inappropriate usage and the intervention targets needed to ensure optimum use.

\section{Methods}

This clinical study was conducted prospectively between 01.10.2018 and 01.10.2019 in the medical and surgical ICUs of Gazi University Faculty of Medicine Hospital, Turkey. The total bed capacity was 55 . Between scheduled dates, all patients older than 18 years of age and using gram-positive spectrum antibiotics (vancomycin, teicoplanin, linezolid, and daptomycin) were included in the study. Recurrence use of gram-positive spectrum antibiotics in the same patients in different times were also included. Patients under the age of 18 years or immunosuppressed patients (neutropenic, and HIV-infected patients with hematologic or solid organ malignancies) were not included in the study.

The demographic and clinical features of the patients were recorded. Besides observations by the clinical staff, the treatments were recorded and evaluated by two infectious diseases specialists and two clinical pharmacists at 24-h intervals from the first day to the last day of treatment. Demographic data of patients (age, sex, body mass index, etc.), presence of comorbid diseases, Charslon comorbidity index, indications for antibiotic treatment, presence of sepsis or septic shock, clinical and laboratory findings (microbiological sampling results, creatinine clearance calculated using the CockcroftGault equation, estimated glomerular filtration rate (eGFR) were recorded. This study was approved by the Institutional Review Board of Gazi University School of Medicine and was conducted according to the Declaration of Helsinki and Good Clinical Practice. (No: 02/ 14.01.2019).

\section{Definitions}

The quality parameters evaluated for inappropriate antibiotic use in this study are given in Table 1.

\section{Inappropriate antibiotic use}

Inappropriate antibiotic use is defined as non-compliance with at least one of the following quality parameters (documented antibiotic indication, appropriate microbiological sampling, appropriate dose, de-escalation and duration of treatment).

\section{Statistical method}

SPSS software for Windows, (version 17, IBM, Armonk, $\mathrm{NY)}$ was used to analyse the data. Categorical variables were presented as number and percentage, and noncategorical variables were presented as mean \pm standard deviation. The Chi-square test was used to compare the categorical variables. The fitness of the non-categorical variables to the normal distribution was evaluated with the Shapiro-Wilk test. The Mann-Whitney U test was used for the comparison of non-normally distributed variables variables respectively. In the univariate analysis, variables with a $p$-value of less than 0.20 and not correlated with each other were included in the logistic regression model. Charlson comorbidity index, use of a central catheter, treatment approach, C-reactive protein (CRP), sepsis, procalcitonin and creatinine levels were included in the logistic regression model. Values with a 
Table 1 The Quality Parameters for Inappropriate use of antibiotics

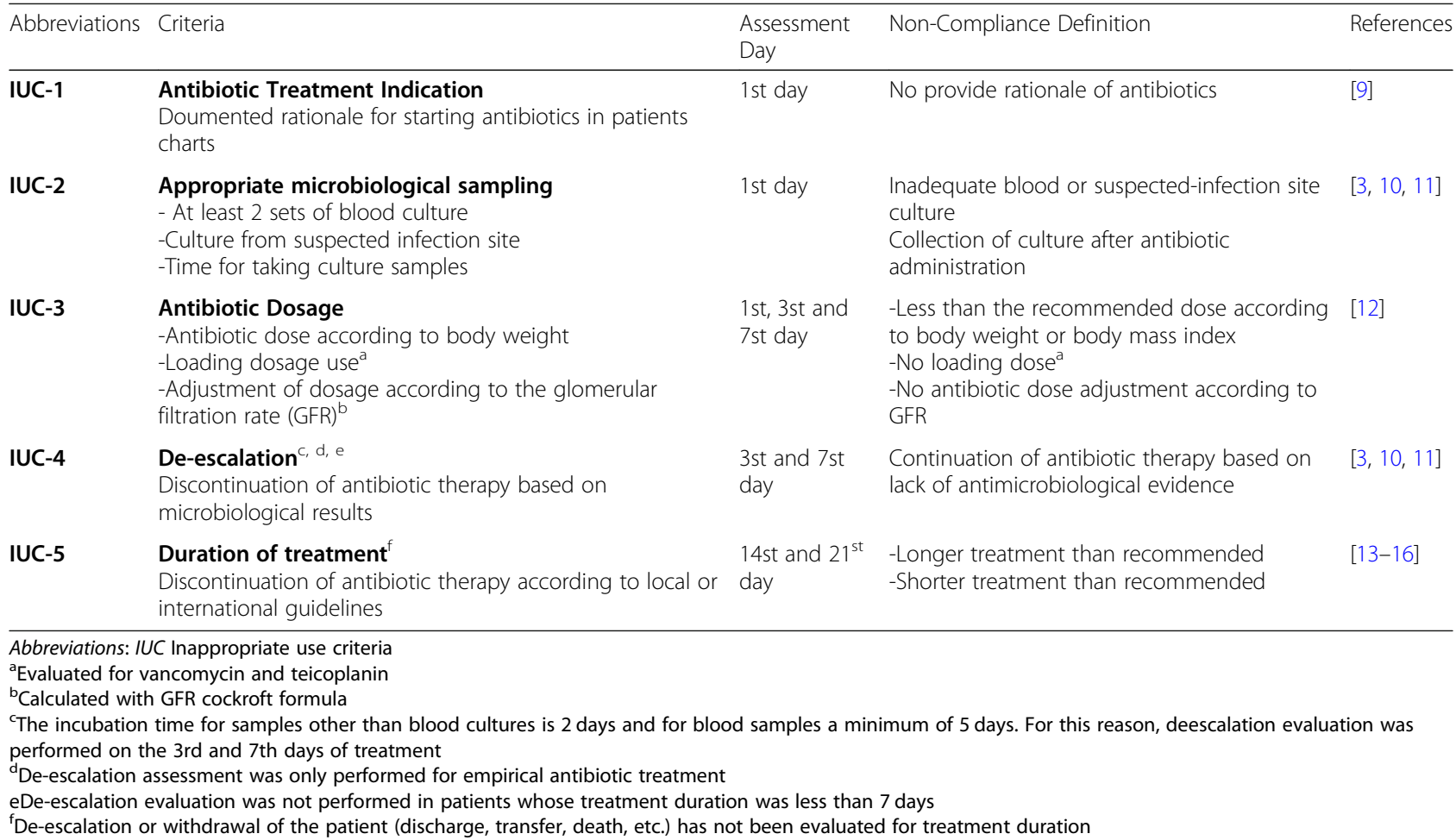

type-I error level of below 5\% were considered as statistically significant.

\section{Results}

During the study period, 200 treatments were evaluated in 169 patients. In 31 patients, gram-positive spectrum antibiotics were used more than ones. The clinical features of the patients were evaluated and are presented in Table 2.

Regarding the use of antibiotics, the incidence of noncompliance with at least one of the determined quality parameters was $83 \%$. The observed levels of noncompliance with the criteria of antibiotic indication, appropriate microbiological sampling, appropriate dosing, de-escalation and duration of treatment were; 47, 28, $26.5-35,61.8-71.5$ and $36 \%$, respectively (Table 3 ).

The determined quality criteria were also evaluated for non-compliance (Fig. 1). The most common inappropriateness for microbiological sampling was found to be associated with insufficient sampling (85.7\%). Dosing errors were often associated with lack of dose adjustment according to renal clearance (54.3\%). Longer duration of antibiotic use was the main reason for treatment duration inappropriateness 77.5 (\%).

Factors associated with inappropriate use of antibiotics were analysed and are presented in Table 4.

Multivariate analysis was performed to evaluate the risk factors for inappropriate antibiotic use, and elevated
Table 2 Clinical features of patients

\begin{tabular}{|c|c|c|}
\hline Variables & $\mathrm{N}$ & $\%$ \\
\hline Age, mean $\pm S D$ & $63.9 \pm 18.7$ & \\
\hline Gender, Female & 79 & 46,7 \\
\hline BMI $\left(\mathrm{kg} / \mathrm{m}^{2}\right)$, mean \pm SD & $26.5 \pm 5.81$ & \\
\hline \multicolumn{3}{|l|}{ Intensive Care Units (ICUs) } \\
\hline Medical ICUs & 95 & 56.2 \\
\hline Surgical ICUs & 74 & 43.8 \\
\hline Duration of hospital stay (day), mean \pm SD & $16.4 \pm 17.8$ & \\
\hline Duration of ICU stay (day), mean \pm SD & $10.2 \pm 14.4$ & \\
\hline $\mathrm{CCl}$, mean $\pm \mathrm{SD}$ & $4.40 \pm 2.43$ & \\
\hline Central venous catheters & 100 & 59.2 \\
\hline Invasive mechanical ventilation & 120 & 71 \\
\hline \multicolumn{3}{|l|}{ Renal failure } \\
\hline $\mathrm{CrCl},(\mathrm{mL} / \mathrm{min}) \geq 50$ & 89 & 52.7 \\
\hline $\mathrm{CrCl},(\mathrm{mL} / \mathrm{min}) 30-49$ & 25 & 14.8 \\
\hline $\mathrm{CrCl},(\mathrm{mL} / \mathrm{min}) 10-29$ & 45 & 26.6 \\
\hline $\mathrm{CrCl},(\mathrm{mL} / \mathrm{min})<10$ & 10 & 5.9 \\
\hline Intermittant renal replacement therapy & 37 & 21.9 \\
\hline Continous renal relacement therapy & 7 & 4.1 \\
\hline
\end{tabular}

Abbreviations: SD standart deviation, BMI Body mass index, ICU Intensive care unit, $\mathrm{CCl}$ Charlson comorbidity index, $\mathrm{CrCl}$ Creatinine clearance 
Table 3 Frequency of inapropriate use of antibiotics (\%)

\begin{tabular}{lccccc}
\hline & 1. Day & 3. Day & 7. Day & 14. Day & Total \\
\hline IUC-1 & 47.0 & & & & \\
IUC-2 & 28.0 & & & & \\
IUC-3 & 26.5 & 35.0 & 35.0 & & \\
IUC-4 & & 78.5 & 61.8 & & \\
IUC-5 & & & & 36.0 & \\
Total & & & & & 83.0
\end{tabular}

Abbreviations: IUC Inappropriate use criteria

creatinin levels were found to increase this risk by approximately two times. (OR; 1.985, 95\% CI 1.196-3.292, $p=0.008$ ) (Table 5).

\section{Discussion}

As per the results of this study, inappropriate grampositive spectrum antibiotics usage in ICUs was as high as $83 \%$. Compliance with the evaluation of de-escalation was very low in the ICUs selected for this study. Renal failure increased the frequency of inappropriate antibiotic use by approximately 2 -fold.

In Turkey, $71.3 \%$ of patients in ICUs are treated with antibiotics [2]. This widespread use is unnecessary and inappropriate. It is recommended that different quality parameters be used to evaluate inappropriate antibiotic usage. Dresser et al. advise considering uncertain indications, continuation of empirical treatment without evidence of infection, unnecessary prophylaxis, and drug contraindications as quality criteria for the evaluation of inappropriate antibiotic use [11].. For similar evaluations,
Kallen et al. recommend considering appropriate microbiological sampling, therapeutic drug monitoring for vancomycin and aminoglycoside, surveillance cultures and periodic sharing of local resistance data [1].. The incidence of inappropriate empirical antibiotic use in ICUs reportedly varies between 14.1 -and $78.9 \%$ due to differences in evaluation criteria $[4,12]$. In Turkey, this incidence ranges from 30 to $50 \%$ [13-15].. The frequency of inappropriate antibiotic use as per our study is higher than that in the literature, since non-compliance with any of the criteria used in the study was considered sufficient to fulfil the definition of inappropriateness [6].

Since 2003, a national antibiotics restriction programme has been implemented in Turkey. Previous studies have shown that these programmes reduce the number of nosocomial infections, length of hospital stay, mortality and microbial resistance rates. The programme has had a positive effect on health expenditures $[3,16,17]$. However, several studies also showed that increased prescriptions of non-restricted antibiotics may eliminate these positive effects $[2,3]$. The results of our study, show that the studied antibiotics, all of which are part of a restricted antibiotics programme, are used inappropriately and with high frequency. This indicates that inappropriate antibiotic use in ICUs cannot be prevented by restriction programmes alone and that the system should be supported by prospective audit and feedback mechanisms [8]. In fact the results of an intervention study conducted by Güçlü et al. was shown that antibiotic restriction programmes can be strengthened by supporting prospective control and feedback mechanisms [3].

The results of our study, revealed the continuation of antibiotics without microbiological evidence, as the most

\section{Reasons for Inappropriate Use of Antibiotics}

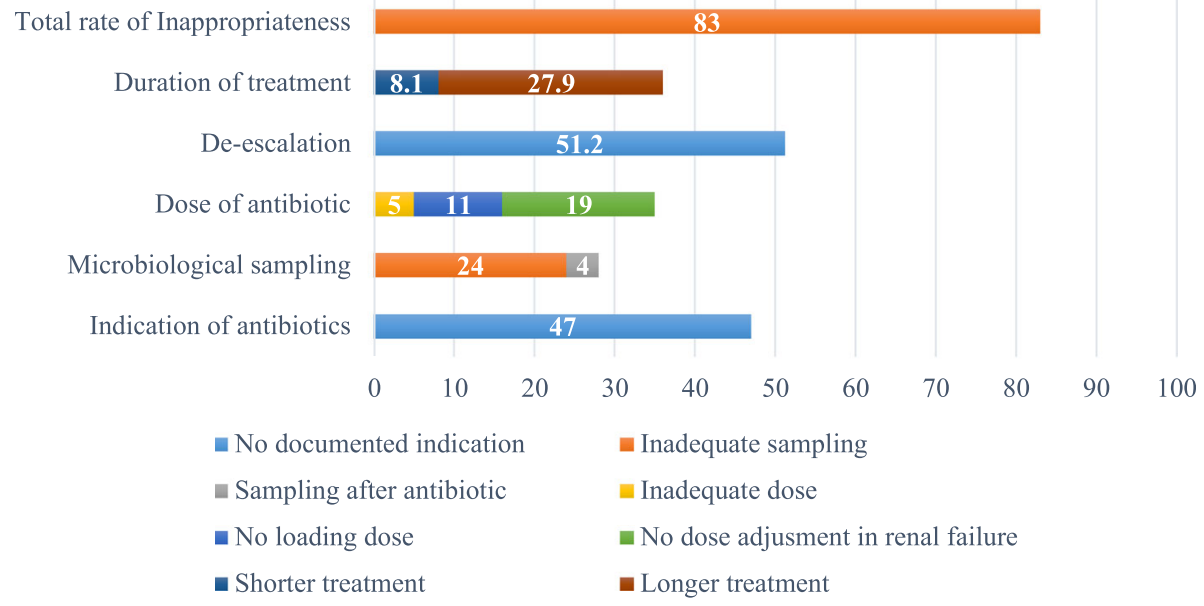

Fig. 1 Reasons for inappropriate use of antibiotics 
Table 4 Factor associated with inappropriate use of antibiotics

\begin{tabular}{|c|c|c|c|}
\hline & $\begin{array}{l}\text { Inapropriate Use } \\
\mathrm{N}(\%)\end{array}$ & $\begin{array}{l}\text { Appropriate Use } \\
\mathrm{N}(\%)\end{array}$ & $P$ value \\
\hline$\overline{\text { Age, } \text { mean } \pm S D^{a}}$ & $64.3 \pm 18.7$ & $61.6 \pm 20.8$ & .522 \\
\hline \multicolumn{4}{|l|}{ Gender $^{\mathrm{b}}$} \\
\hline Female & $78(47)$ & $16(47.1)$ & \multirow[t]{2}{*}{.994} \\
\hline Male & $88(53)$ & $18(52.9)$ & \\
\hline $\mathrm{BMI}\left(\mathrm{kg} / \mathrm{m}^{2}\right)$, mean $\pm \mathrm{SD}^{\mathrm{a}}$ & $26.3 \pm 6.24$ & $27.0 \pm 5.68$ & .228 \\
\hline$C C l$, mean $\pm \mathrm{SD}^{\mathrm{a}}$ & $4.51 \pm 2.48$ & $3.82 \pm 2.35$ & .200 \\
\hline \multicolumn{4}{|l|}{$I C U^{b}$} \\
\hline Medical & $95(57.2)$ & $20(58.8)$ & \multirow[t]{2}{*}{.864} \\
\hline Surgical & $71(42.8)$ & $14(41.2)$ & \\
\hline Duration of Hospital Stay \pm SD ${ }^{a}$ (Day) & $23.2 \pm 27.0$ & $20.9 \pm 26.6$ & .439 \\
\hline Duration of ICU stay $\pm S D^{a}$ (Day) & $16.8 \pm 25.8$ & $16.5 \pm 27.6$ & .591 \\
\hline \multicolumn{4}{|l|}{ Source of Infection ${ }^{b}$} \\
\hline Sepsis & $70(49.3)$ & $9(29)$ & .040 \\
\hline Septic Schock & $59(30.5)$ & $7(20.6)$ & .091 \\
\hline Pneumoniae & $111(66.9)$ & $20(58.8)$ & .369 \\
\hline Blood Stream Infection (BSI) & $46(27.9)$ & $5(14.7)$ & .109 \\
\hline Others & $20(12.0)$ & $11(32.4)$ & .003 \\
\hline Unknown & $32(19.3)$ & $3(8.8)$ & .118 \\
\hline \multicolumn{4}{|l|}{ Antibiotic treatment approach ${ }^{\mathrm{b}}$} \\
\hline Emprical therapy & $114(68.7)$ & $18(52.9)$ & \multirow[t]{2}{*}{.078} \\
\hline Agent spesific therapy & $52(31.3)$ & $16(47.1)$ & \\
\hline Central Venous Catheter & $109(65.7)$ & $16(47.1)$ & .041 \\
\hline \multicolumn{4}{|l|}{ Laboratory Paremeters $^{\mathrm{a}}$} \\
\hline WBC $\left(\times 10 . \mathrm{e}^{3} / \mu \mathrm{L}\right)$, mean $\pm S D$ & $14.672 \pm 19.179$ & $14.802 \pm 10.087$ & .460 \\
\hline $\operatorname{PLT}\left(\times 10 . \mathrm{e}^{3} / \mu \mathrm{L}\right)$, mean $\pm \mathrm{SD}$ & $221.879 \pm 139.955$ & $244.323 \pm 156.829$ & .482 \\
\hline Lactate $(\mathrm{mMol} / \mathrm{L})$, mean $\pm \mathrm{SD}$ & $2.06 \pm 1.70$ & $2.22 \pm 1.91$ & .644 \\
\hline $\mathrm{GFR}(\mathrm{mL} / \mathrm{min})$, mean $\pm \mathrm{SD}$ & $50.6 \pm 32.5$ & $69.4 \pm 26.8$ & .001 \\
\hline $\mathrm{Cr}(\mathrm{mg} / \mathrm{dL})$, mean $\pm \mathrm{SD}$ & $1.93 \pm 1.74$ & $0.90 \pm 0.79$ & $<.001$ \\
\hline $\mathrm{CRP}(\mathrm{mg} / \mathrm{L})$, mean $\pm \mathrm{SD}$ & $133 \pm 92.8$ & $156 \pm 112$ & .041 \\
\hline Procalcitonin $(\mathrm{ng} / \mathrm{mL})$, mean $\pm \mathrm{SD}$ & $18.7 \pm 85.5$ & $14.9 \pm 68.5$ & .013 \\
\hline
\end{tabular}

Abbreviations: SD standart deviation, BMI Body mass index, CCI Charslon comorbidity index, ICU Intensive care unit, WBC White blood cell, PLT Platelet, GFR Glomerular filtration rate, $\mathrm{Cr}$ Creatinine, $C R P$ C-reactive protein

${ }^{a}$ Mann-Whitney $\mathrm{U}$ test was used

${ }^{\mathrm{b}}$ Chi-squared test was used

common factor adding to their inappropriate use. In ICUs, the de-escalation algorithm reduces the duration of treatment and frequency of microbial resistance without increasing mortality $[3,18-20]$. Other studies conducted in Turkey, indicate such de-escalation is necessary in $10 \%$ of the cases [15]. On the other hand, the necessity of de-escalation in ICUs was shown to be higher. Mutters et al. reported that compliance with the evaluation of therapy discontinuation or de-escalation ranged from $2.4-8 \%$ [21]. In our study, the compliance in the early period of de-escalation ( 3 days) was found to be quite low. The frequency of de-escalation was slightly higher in the late period ( 5 days). Considering that the frequency of appropriate microbiological sampling is high, the above results may be attributed to late results (blood cultures) or late recognition. Despite the increased frequency compared to that in the early period, the frequency of late de-escalation was found to be low. The unwillingness of clinicians to discontinue treatment despite the results of the cultures is likely the important reason for this result. It appears that the restricted antibacterial programme alone does not seem to be 
Table 5 Risk Factors for Inappropriate Antibiotic Use in Logistic Regression Analysis

\begin{tabular}{llllll}
\hline & B & S.E & Sig. & O.R & \% 95 C.I \\
\hline CCl & -.042 & .093 & .650 & .959 & $.799-1.150$ \\
Sepsis & -.552 & .776 & .477 & .576 & $.126-2.635$ \\
Antibiotic tretament approach & -.504 & .442 & .255 & .604 & $.254-1.438$ \\
Central venous catheter & .322 & .415 & .438 & 1.380 & $.612-3.112$ \\
CRP & -.003 & .002 & .136 & .997 & $.993-1.001$ \\
Procalcitonin & .000 & .002 & .889 & 1.00 & $.995-1.005$ \\
Creatinine & .685 & .258 & .008 & 1.985 & $1.196-3.292$ \\
\hline
\end{tabular}

Abbreviations: $B$ unstandardized regression weight, $C l$ confidence interval, $O R$ odds ratio, SE standard error, CCI Charslon comorbidity index, CRP

C-reactive protein

sufficient for proper de-escalation in ICUs. Therefore it is crucial to develop an effective de-escalation strategy supported by local treatment guidelines.

Another important reason for inappropriate antibiotic usage in our study was the lack of proper antibiotic dose adjustment according to the eGFR. Renal failure and renal replacement therapies (RRTs), cause plasma concentration changes and affect drug concentrations [5]. RRTs, especially the continuous type, have also been shown to cause significant pharmacokinetic changes on the antibiotic groups that were evaluated in this work [22-24]. Therefore, antibiotic doses may remain suboptimal in ICU patients when compared to the normal population $[5,25,26]$.. The frequency of RRTs in our study was $21.7 \%$. Moreover, $6.7 \%$ of all patients received continuous RRT during the study. Also, elevated creatinine serum levels were found to be the major risk factor for the inappropriate use of antibiotics. Therefore, creatinine clearance changes need to be periodically evaluated to determine appropriate doses of antibiotics in collaboration with clinical pharmacists, infectious diseases specialists and clinical staff in ICUs [5].

There is study suffers from several limitations First, our data were collected from a single centre and the appropriateness of antibiotics was evaluated only for antibiotics effective against gram-positive microorganisms. These limitations prevent general assessments of the effectiveness of the national antibiotic restriction programme. Second, no global consensus currently exists on the criteria for evaluatng the inappropriate use of antibiotics in ICUs. Using different criteria may limit the applicability of the our study results. Third, this work did not evaluate the outcome measures related with the inappropriate use of antibiotics, such as mortality, duration of hospital or ICU stay, changing antimicrobial resistance patterns, and secondary infections (e.g. C. difficile infections). Despite all these limitations, this study successfully provided important insights into the appropriateness of antibiotic use towards improving the ASP. These results should be validated in the future via an interventional (before-after) study.

\section{Conclusion}

In spite of the restricted antibiotic programme, inappropriate antibiotic use in ICUs is quite common. Appropriate use of antibiotics should be audited with predetermined quality parameters. In particular, it is necessary to establish local guidelines in collaboration with different disciplines for the determination and follow-up of de-escalation and optimal treatment doses. In patients undergoing RRT with increased risk of suboptimal concentration, antibacterial treatment doses should be individualized and closely monitored.

\section{Abbreviation}

ASP: Antimicrobial Stewardship Programme; eGFR: estimated Glomerular Filtration Rate; HIV: Human Immunodeficiency Virus, ICU: Intensive Care Unit; RRT: Renal Replacement Therapy; CRP: C-reactive protein

\section{Acknowledgements}

We would like to thank both reviewers of this article for their valuable suggestions.

\section{Authors' contributions}

$\mathrm{HSO}$ and $\mathrm{KH}$ designed the study; DMF, KE, and AA collected datas; HSO interpreted the results, and wrote the manuscript. All the authors read and approved the final manuscript.

\section{Funding}

The authors received no specific funding for this work

The authors whose names are listed immediately below certify that they have NO affiliations with or involvement in any organization or entity with any financial interest or non-financial interest in the subject matter or materials discussed in this manuscript.

\section{Availability of data and materials}

All data generated or analysed during this study are included in this published article.

\section{Ethics approval and consent to participate}

This study was approved by the Institutional Review Board of Gazi University School of Medicine, Ankara/ (Turkey) and was conducted according to the Declaration of Helsinki and Good Clinical Practice. (No:02/14.01.2019). Written informed consent was obtained from the adult ( $>18$ years old) patients who participated in this study.

Consent for publication

Not applicable.

\section{Competing interests}

The authors declare that they have no competing interests.

\section{Author details}

${ }^{1}$ Faculty of Medicine, Department of Infectious Diseases, Gazi University, Ankara, Turkey. ${ }^{2}$ Faculty of Pharmacy, Department of Clinical Pharmacy, Gazi University, Ankara, Turkey.

Received: 24 December 2019 Accepted: 31 March 2020

Published online: 19 April 2020

\section{References}

1. Kallen MC, Roos-Blom MJ, Dongelmans DA, Schouten JA, Gude WT, de Jonge E, Prins JM, de Keizer NF. Development of actionable quality indicators and an action implementation toolbox for appropriate antibiotic use at intensive care units: a modified-RAND Delphi study. PLoS One. 2018; 13(11):e0207991. 
2. Guclu E, Ogutlu A, Karabay O, Demirdal T, Erayman I, Hosoglu S, Turhan V, Erol S, Oztoprak N, Batirel A. Antibiotic consumption in Turkish hospitals; a multi-Centre point prevalence study. J Chemother. 2017;29(1):19-24.

3. Schuts EC, Hulscher ME, Mouton JW, Verduin CM, Stuart JWC, Overdiek HW, van der Linden PD, Natsch S, Hertogh CM, Wolfs TF. Current evidence on hospital antimicrobial stewardship objectives: a systematic review and meta-analysis. The Lancet Infect Dis. 2016;16(7):847-56.

4. Marquet K, Liesenborgs A, Bergs J, Vleugels A, Claes N. Incidence and outcome of inappropriate in-hospital empiric antibiotics for severe infection: a systematic review and meta-analysis. Crit Care. 2015;19(1):63.

5. Luyt C-E, Bréchot N, Trouillet J-L, Chastre J. Antibiotic stewardship in the intensive care unit. Crit Care. 2014;18(5):480.

6. van den Bosch CM, Geerlings SE, Natsch S, Prins JM, Hulscher ME. Quality indicators to measure appropriate antibiotic use in hospitalized adults. Clin Infect Dis. 2014;60(2):281-91.

7. Scott CL, Brown E, Charani E, Michie S, Ramsay CR, Marwick CA, Davey P. Interventions to improve antibiotic prescribing practices for hospital inpatients (updated protocol). Cochrane Database Syst Rev. 2017;2017(2): 28-30.

8. Barlam TF, Cosgrove SE, Abbo LM, MacDougall C, Schuetz AN, Septimus EJ, Srinivasan A, Dellit TH, Falck-Ytter YT, Fishman NO. Implementing an antibiotic stewardship program: guidelines by the Infectious Diseases Society of America and the Society for Healthcare Epidemiology of America. Clin Infect Dis. 2016;62(10):e51-77.

9. Molayi A, Kirk A, Markley J, Bernard S, Taylor P, Sanogo K, Lee K, Pakyz A, Doll $M$, Bearman G. Description of a restriction program for gram-positive antimicrobial agents at an academic medical center. Am J Infect Control. 2018:46(2):232-4.

10. Cowley MC, Ritchie DJ, Hampton N, Kollef MH, Micek ST. Outcomes associated with de-escalating therapy for methicillin-resistant Staphylococcus aureus in culture-negative nosocomial pneumonia. Chest. 2019;155(1):53-9.

11. Dresser LD, Bell CM, Steinberg M, Ferguson ND, Lapinsky S, Lazar N, Murphy $P$, Singh JM, Morris AM. Use of a structured panel process to define antimicrobial prescribing appropriateness in critical care. J Antimicrob Chemother. 2017;73(1):246-9.

12. Paul M, Shani V, Muchtar E, Kariv G, Robenshtok E, Leibovici L. Systematic review and meta-analysis of the efficacy of appropriate empiric antibiotic therapy for sepsis. Antimicrob Agents Chemother. 2010;54(11):4851-63.

13. Erbay A, İdil A, Gözel MG, Mumcuoğlu İ, Balaban N. Impact of early appropriate antimicrobial therapy on survival in Acinetobacter baumannii bloodstream infections. Int J Antimicrob Agents. 2009;34(6):575-9.

14. Ergül AB, Gökçek I, Çelik T, Torun YA. Assessment of inappropriate antibiotic use in pediatric patients: point-prevalence study. Turk Pediatr Arsivi. 2018; 53(1):17.

15. Şengel BE, Bilgin H, Bilgin BÖ, Gidener T, Saydam S, Pekmezci A, Ergönül Ö, Korten $\mathrm{V}$. The need for an antibiotic stewardship program in a hospital using a computerized pre-authorization system. Int J Infect Dis. 2019;82:40-3.

16. Altunsoy A, Aypak C, Azap A, Ergönül Ö, Balık I. The impact of a nationwide antibiotic restriction program on antibiotic usage and resistance against nosocomial pathogens in Turkey. Int J Med Sci. 2011;8(4):339.

17. Abbara S, Pitsch A, Jochmans S, Hodjat K, Cherrier P, Monchi M, Vinsonneau C, Diamantis S. Impact of a multimodal strategy combining a new standard of care and restriction of carbapenems, fluoroquinolones and cephalosporins on antibiotic consumption and resistance of Pseudomonas aeruginosa in a French intensive care unit. Int J Antimicrob Agents. 2019; 53(4):416-22.

18. De Bus L, Denys W, Catteeuw J, Gadeyne B, Vermeulen K, Boelens J, Claeys G, De Waele JJ, Decruyenaere J, Depuydt PO. Impact of de-escalation of beta-lactam antibiotics on the emergence of antibiotic resistance in ICU patients: a retrospective observational study. Intensive Care Med. 2016;42(6): 1029-39.

19. Montravers P, Augustin P, Grall N, Desmard M, Allou N, Marmuse J-P, Guglielminotti J. Characteristics and outcomes of anti-infective de-escalation during health careassociated intra-abdominal infections. Crit Care. 2016;20(1):83.

20. Arda B, Sipahi OR, Yamazhan T, Tasbakan M, Pullukcu H, Tunger A, Buke C, Ulusoy S. Short-term effect of antibiotic control policy on the usage patterns and cost of antimicrobials, mortality, nosocomial infection rates and antibacterial resistance. J Inf Secur. 2007;55(1):41-8.

21. Mutters NT, De Angelis G, Restuccia G, Di Muzio F, Schouten J, Hulscher M, Antonelli M, Tacconelli E. Use of evidence-based recommendations in an antibiotic care bundle for the intensive care unit. Int J Antimicrob Agents. 2018;51(1):65-70.

22. Roger C, Muller L, Wallis S, Louart B, Saissi G, Lipman J, Lefrant J, Roberts J. Population pharmacokinetics of linezolid in critically ill patients on renal replacement therapy: comparison of equal doses in continuous venovenous haemofiltration and continuous venovenous haemodiafiltration. J Antimicrob Chemother. 2015;71(2):464-70.

23. Soraluce A, Asín-Prieto E, Rodríguez-Gascón A, Barrasa H, Maynar J, Carcelero E, Soy D, Isla A. Population pharmacokinetics of daptomycin in critically ill patients. Int J Antimicrob Agents. 2018;52(2):158-65.

24. Economou CJ, Kielstein JT, Czock D, Xie J, Field J, Richards B, Tallott M, Visser A, Koenig C, Hafer C. Population pharmacokinetics of vancomycin in critically ill patients receiving prolonged intermittent renal replacement therapy. Int J Antimicrob Agents. 2018;52(2):151-7.

25. Leone M, Roberts JA, Bassetti M, Bouglé A, Lavigne J-P, Legrand M, Neely M Paiva J-A, Payen D, Rello J. Update in antibiotic therapy in intensive care unit: report from the 2019 Nîmes International Symposium. Anaesth Crıt Care Pain Med. 2019;38:12-13.

26. Rello Condomines J. DALI defining antibiotic levels in intensive care unit patients are current beta-lactam antibiotic doses sufficient for critically ill patients. Clin Infect Dis. 2014;58(núm 8):1-1072-83.2014.

\section{Publisher's Note}

Springer Nature remains neutral with regard to jurisdictional claims in published maps and institutional affiliations.
Ready to submit your research? Choose BMC and benefit from:

- fast, convenient online submission

- thorough peer review by experienced researchers in your field

- rapid publication on acceptance

- support for research data, including large and complex data types

- gold Open Access which fosters wider collaboration and increased citations

- maximum visibility for your research: over $100 \mathrm{M}$ website views per year

At BMC, research is always in progress.

Learn more biomedcentral.com/submissions 